\title{
A virada retórica para a convivialidade nas redes sociais: estudo de caso da interface gráfica do Linkedln
}

\author{
The rhetorical turn toward conviviality in social media: LinkedIn's \\ graphical interface case analysis
}

André Diego Bernardes Ferreira, Gabriela Araujo F. Oliveira

linguagem gráfica, variáveis da informação, rede social, linkedin

Este artigo apresenta um estudo de caso da virada retórica para a convivialidade no redesenho da rede social Linkedln. Por meio deste estudo, apresentamos as similaridades em comparação às interfaces gráficas de outras redes sociais, como Facebook e Twitter. Para analisar os recursos gráficos e estruturais, foram necessários conceitos de semiótica, linguagem gráfica visual, arquitetura de informação e design de interação. Assim, realizamos uma análise inicial da página home do Linkedln a partir dos fatores variáveis da estrutura operacional da linguagem gráfica, com o objetivo de explicitar a configuração, os aspectos gráficos e os diferentes tipos de linguagens utilizadas na interface. Concluímos que, embora o Linkedln declare um propósito diferente de outras redes sociais, ele se apresenta e encoraja interações de maneira extremamente similar.

graphic language, information variables, social network, linkedin

This paper presents a case study of the rhetorical turn toward conviviality in the redesign of Linkedln, a social media platform. With this study we present similarities in comparison to other social media's graphic user interface, such as Facebook and Twitter. To analyse graphic and structural resources we employed concepts from semiotics, visual graphic language, information architecture and interaction design. Then, we made an initial analysis of the home page on Linkedln considering an operational framework that identifies several variable factors, aiming to delineate the configuration, the graphic aspects and the visual languages employed in the interface. Thus, even though Linkedln declares a different purpose from other social media, it presents itself and encourages interactions in a remarkable similar manner.

\section{Introdução e fundamentação teórica}

A internet tornou-se parte importante da realidade social e, assim, ganhou espaço no campo da semiótica. Para Santaella (2005), semiótica é uma ciência cujo objeto de investigação são todos os tipos de linguagens, que tem por objetivo examinar qualquer fenômeno de produção de significado. Para Hall (2008), os signos sempre são criados e consumidos por uma sociedade específica. Na sociedade ocidental contemporânea, largamente alienada e consumista, é comum nos comunicarmos por meio de metáforas relacionadas ao consumo, como se o tempo fosse uma mercadoria a ser negociada: ganhar tempo, perder tempo,

Anais do $10^{\circ} \mathrm{CIDI}$ e $10^{\circ} \mathrm{CONGIC}$

Kelli C.A.S. Smythe, Rafael de Castro Andrade (orgs.)

Sociedade Brasileira de Design da Informação - SBDI

Curitiba | Brasil | 2021
Proceedings of the $10^{\text {th }} \mathrm{CIDI}$ and $10^{\text {th }}$ CONGIC

Kelli C.A.S. Smythe, Rafael de Castro Andrade (orgs.)

Sociedade Brasileira de Design da Informação - SBDI Curitiba | Brazil | 2021 
tempo é dinheiro etc. Assim, a linguagem, enquanto veículo de comunicação, tem impacto direto na nossa realidade.

De maneira mais específica em relação à linguagem, Twyman (1979) propõe dois canais: auditivo (verbal ou não-verbal) e visual (gráfico ou não gráfico). Disso, ele classifica o modo de representação da linguagem. Para este artigo, focaremos no campo referente à linguagem visual gráfica - que compreende elementos produzidos com a intenção de comunicar uma mensagem, que pode ser representada a partir do modo verbal, pictórico e/ou esquemático de acordo com a figura a seguir (Figura 1).

Figura 1: Esquema descritivo sobre linguagem de Twyman (1985), traduzido pelos autores. (Fonte: Twyman, 1985).

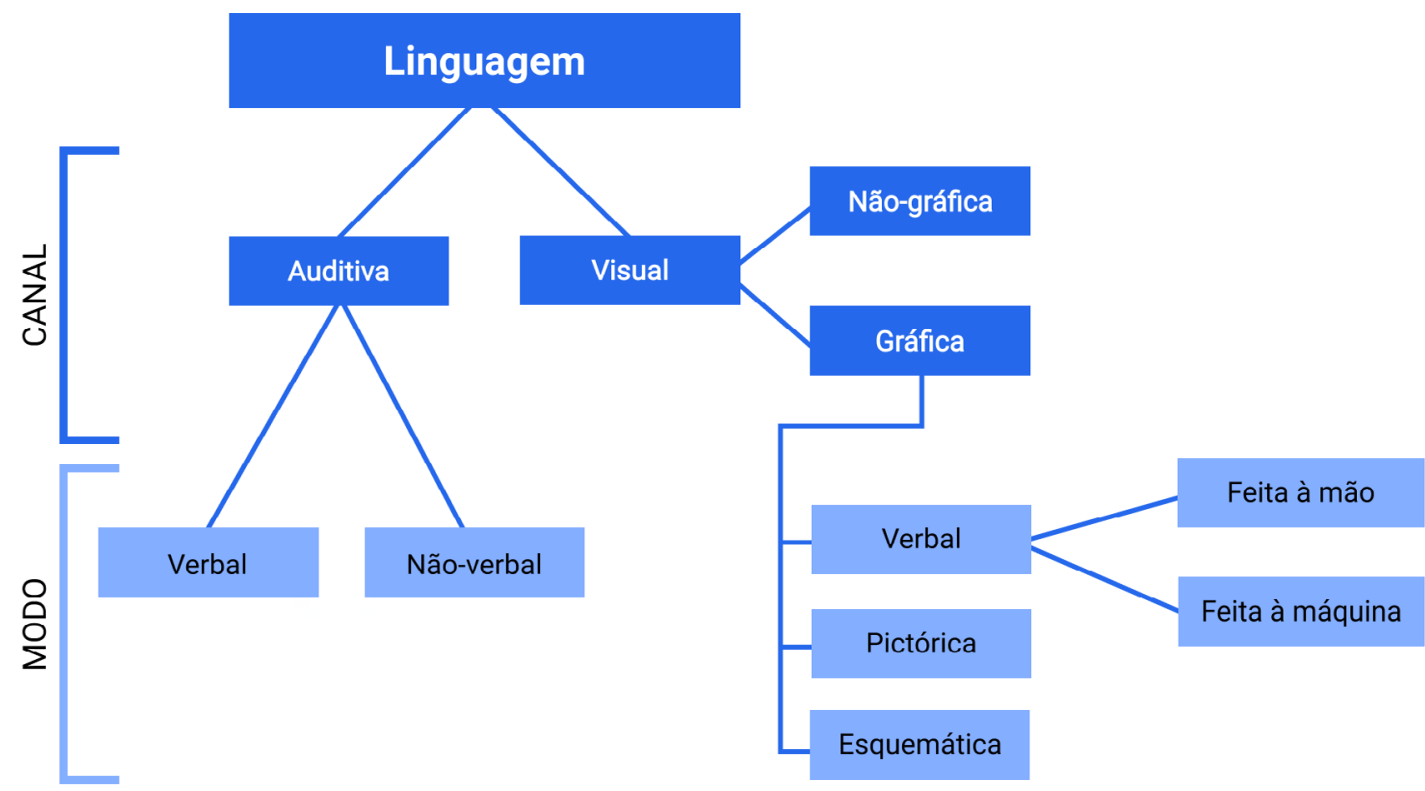

Para Twyman (1985), a linguagem verbal é a representação gráfica da linguagem falada (seja ela feita à máquina ou escrita à mão). Já a linguagem pictórica comporta imagens produzidas artificialmente "que remetem por mais remota que seja à aparência ou estrutura de algo real ou imaginado" (Twyman, 1985, p. 249). Por fim, a linguagem esquemática compreende formas gráficas que não incluem palavras, números ou imagens pictóricas (como por exemplo, tabelas, representações abstratas de estrutura etc.)

Além disso, Twyman (1985) também apresenta algumas variáveis referentes ao uso da linguagem gráfica:

- Propósito: se o objetivo da informação é de informar ou persuadir;

- Conteúdo informacional: caracteriza a essência da informação ou da mensagem que será transmitida;

- Configuração: identifica diferentes formas de organização espacial dos elementos gráficos da linguagem; 
- Modo: seja verbal, pictórica, esquemática ou a combinação entre elas;

- Meios de produção: desde produzidos à mão ou por computador;

- Recursos: em termos de habilidades, facilidades, fundos e tempos disponíveis;

- Usuários: considera fatores como idade, habilidade, treinamento, interesses e experiência anterior;

- Circunstâncias de uso: Se o usuário está trabalhando em uma biblioteca bem equipada ou em circunstâncias estressantes em um veículo em movimento.

A tecnologia da informação há anos vem transformando a maneira como as pessoas se comunicam, como consomem conteúdo, e, também, como se candidatam a uma vaga de trabalho. Um dos ingredientes indispensáveis para a fluidez dessa transformação é a arquitetura da informação, que visa expandir as capacidades humanas de localização de informação em ambientes de complexidade alternadas.

A arquitetura da informação é a prática que se ocupa do projeto de espaços informacionais e de seus aspectos sociais, culturais e tecnológicos. Por isso, tem um papel fundamental na nossa sociedade (Agner, 2018, p. 111).

Arquitetura da informação, termo cunhado por Richard Saul Wurman em 1970, tem a missão de organizar informações, padronizar dados e transformar o que é confuso e complexo em algo claro e de fácil acesso para as pessoas. Sua meta é promover a encontrabilidade e compreensibilidade das informações, como aponta Agner (2018, p. 104).

Acerca do uso da linguagem visual em interfaces, Krug (2014) defende que as pessoas só utilizarão um site ou produto digital se conseguirem navegar e encontrar uma determinada informação de forma satisfatória. Nesse sentido, Yablonski (2020) enfatiza que as pessoas preferem que um sistema funcione da mesma maneira de outros já conhecidos. No Linkedln, é possível observar "algumas dinâmicas latentes que atualmente orientam as redes sociais e, portanto, a sociedade como um todo" (Lorusso, 2017, p.65), o que aponta alguns indícios da retórica da convivialidade nas suas interface, comunicação e origem.

A configuração desses sistemas é parte das atribuições do design de interação. Rogers (2013) defende que design de interação é projetar produtos interativos para auxiliar a comunicação e interação das pessoas em casa ou no trabalho. Uma possível plataforma para essas interações são as redes sociais, que Unger e Chandler (2009) descrevem como um sistema baseado em tarefas, em que o usuário precisa executar buscas, adicionar pessoas, gerenciar seus perfis, enviar mensagens e receber notificações.

Nesse sentido, analisaremos a interface gráfica do Linkedln, fundada em dezembro de 2002 e lançada em maio de 2003. A rede social foi incipientemente utilizada por profissionais de diversas áreas de formação ao redor do globo e, em 2007, atingiu a marca de 16 milhões de usuários. Nesse período, o Linkedln apresentava funcionalidades anômalas e peculiares em comparação a outras redes sociais generalistas, afirma Lorusso (2017) (Figura 2). 
Figura 2: Página home do Linkedln de 2012, imagem extraída do blog oficial da empresa em: https://blog.linkedin.com/2012/07/16/introducing-a-simpler-homepage.

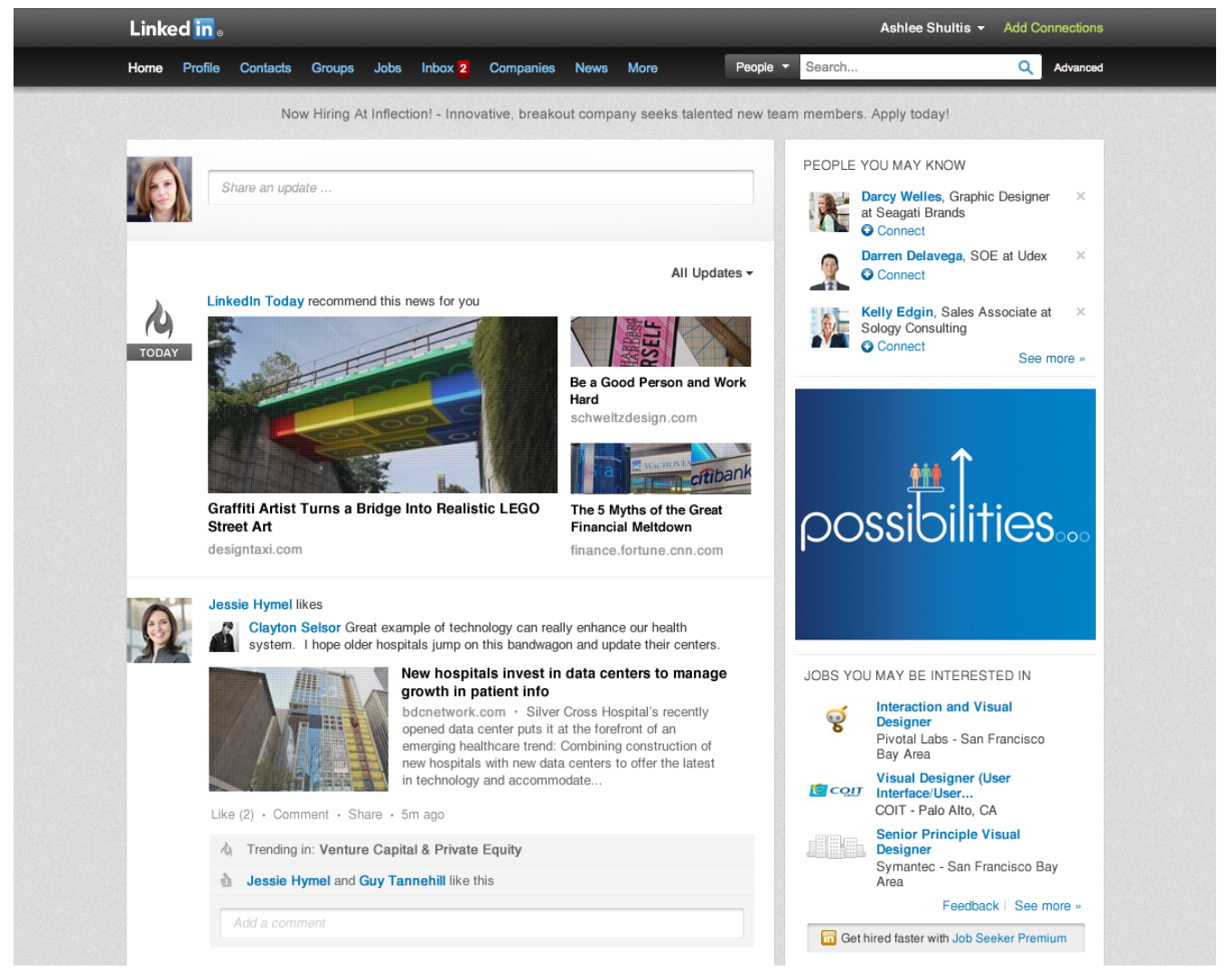

Ao compararmos a economia de likes do Facebook e a base das hashtags do Twitter é possível visualizar a quase total insignificância que o Linkedln passou por vários anos - pouco mencionado em revistas e jornais e quase sempre citado de maneira célere. Evelyn Rusli, redatora de tecnologia no The Wall Street Journal, escreveu um artigo intitulado Linkedin: The Ugly Duckling of Social Media (2013), no qual relata que o Linkedln, por utilizar um modelo de negócio híbrido para consumidor e empresa, criou um negócio dependente da adoção dos consumidores para vender serviços para empresas, sendo visto por muito tempo como o patinho feio das redes sociais.

Nos últimos anos, segundo o CEO do Linkedln Jeff Weiner (2016), a utilização da plataforma tem crescido de maneira significativa: os jovens profissionais tendem a manter o perfil constantemente atualizado, mesmo que não insiram novas experiências profissionais na busca por vagas de emprego. Dessa maneira, acredita-se que essa mudança de comportamento representa um compromisso mais profundo com a plataforma. Isso parece ter relação com o profundo redesenho da plataforma, apresentado em 2017, que a adequou aos padrões visuais e funcionais de empresas como Google e Facebook.

Ou seja, ao adequar sua interface aos mesmos padrões de outras redes, o Linkedln apresentou uma virada retórica em direção ao convívio (Davies, 2016; Lorusso, 2017). Hoje é possível notar a similaridade entre as redes sociais, os mesmos padrões de notificação, estrutura e configuração similares, reações em publicações com utilização de emojis. A retórica da convivialidade, conforme delineada por Davies (2016), é uma estratégia utilizada pelas 
empresas de tecnologia que exploram as relações sociais mediadas por plataformas, pois "diversidade cultural e sociabilidade informal são crescentemente consideradas recursos cruciais de vantagens competitivas" (s.p.). A funcionalidade de "criar publicação" aponta o padrão que pode ser percebido na Figura 3.

Figura 3: Captura de tela do campo de publicação no feed do Linkedln, Facebook e Twitter.

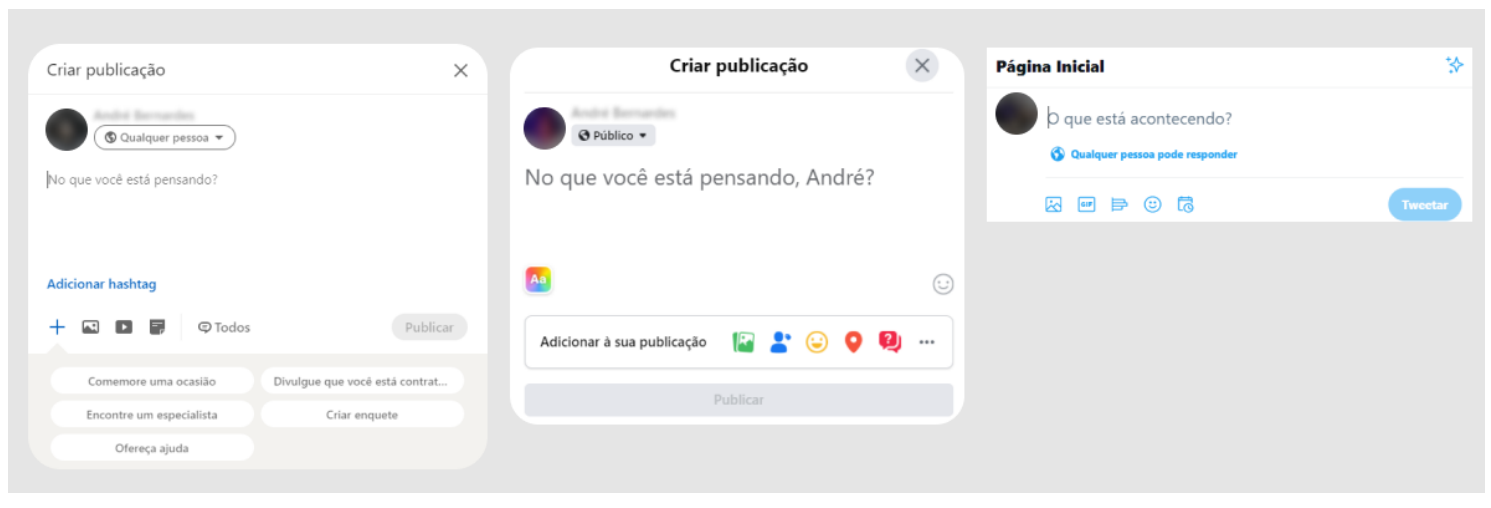

Davies (2016) reflete sobre a virada retórica e como isso foi utilizado para prender nossa atenção e nos manter engajados. Quando nos deparamos com perguntas como "No que você está pensando?" ou "O que está acontecendo?", em teoria poderia ser entendido como um simples pedido de informação concreta. Mas na prática acontece que, ao transmitirmos informações sobre acontecimentos, sentimentos e pensamentos, o sistema automaticamente gera uma varredura neural que entrelaça as informações compartilhadas à publicidades, sugestões e ao engajamento por associação.

O objetivo deste parágrafo que antecede a análise gráfica realizada na página home do Linkedln, é uma forma de contextualizar e reforçar que as informações produzidas pelos usuários das redes sociais são o combustível para a geração de mais informação direcionada para o engajamento contínuo de seus utilizadores.

\section{Análise gráfica da home do Linkedln}

No presente estudo de caso, realizamos uma análise inicial da interface da página home do LinkedIn utilizando como base as variáveis de Twyman (1985), com o objetivo de observar os aspectos gráficos e configuração da estrutura, identificar os diferentes tipos de linguagens utilizadas por seus usuários para transmitir uma mensagem. Desta forma, o conteúdo do feed não interferiu em nossa análise.

\section{Propósito}

Iniciamos pela identificação da variável propósito, o Linkedln apesar de ser caracterizada como uma rede social, seu principal objetivo é ajudar profissionais a criar e aumentar sua rede de contatos ou seu Networking. Na rede social, as pessoas compartilham experiências, coisas do dia a dia da profissão, conteúdos informativos e educativos (Figura 4). 
Figura 4: Página home de um dos autores deste estudo no Linkedln.

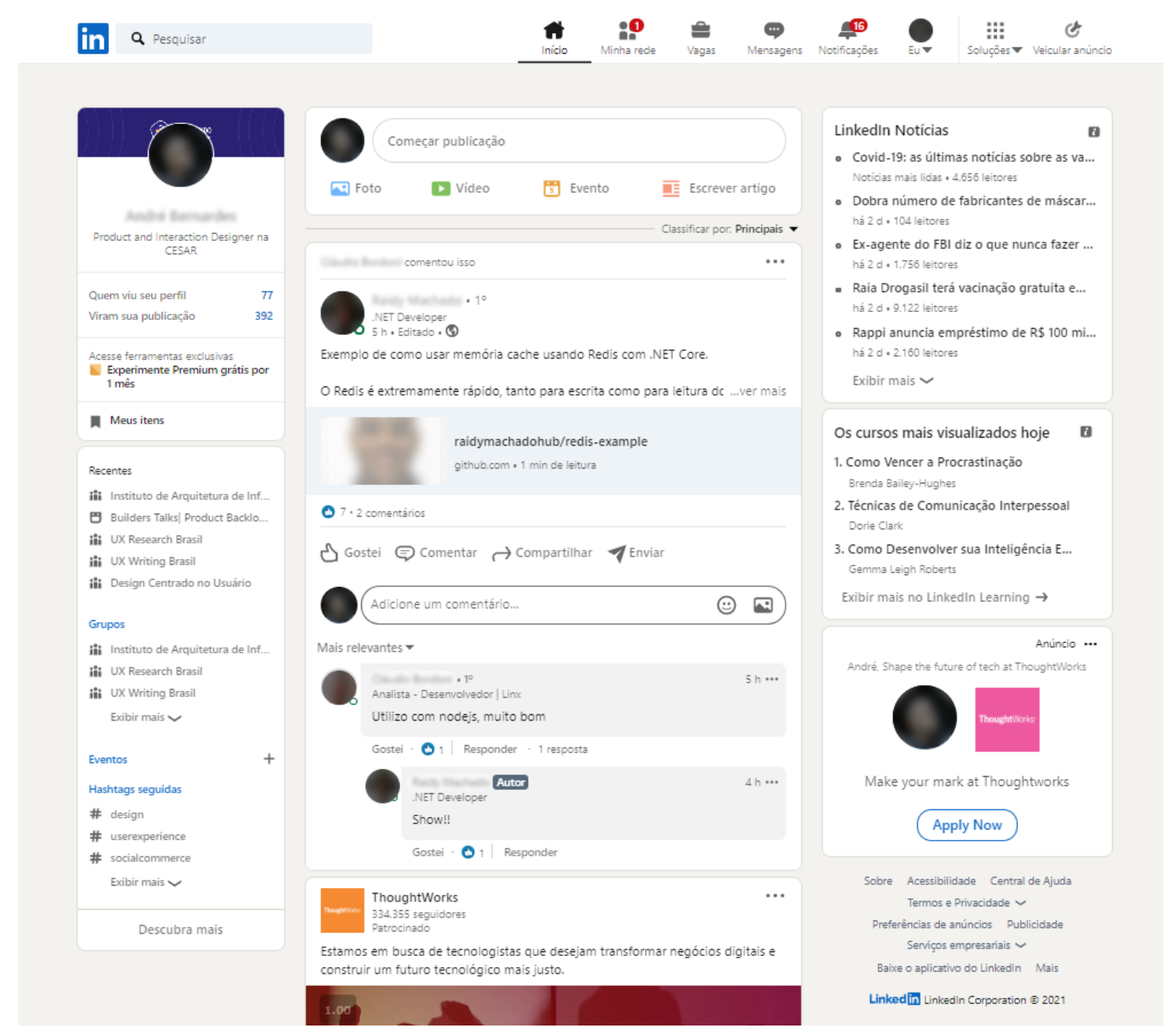

\section{Conteúdo informacional}

Na segunda variável, é possível identificar diversas modalidades de informação, desde a utilização de textos curtos e longos, textos como suporte de imagem, apenas imagens, vídeos e links. Buscamos identificar essa formatação na (figura 5). 
Figura 5: Análise da configuração da página home do Linkedln.

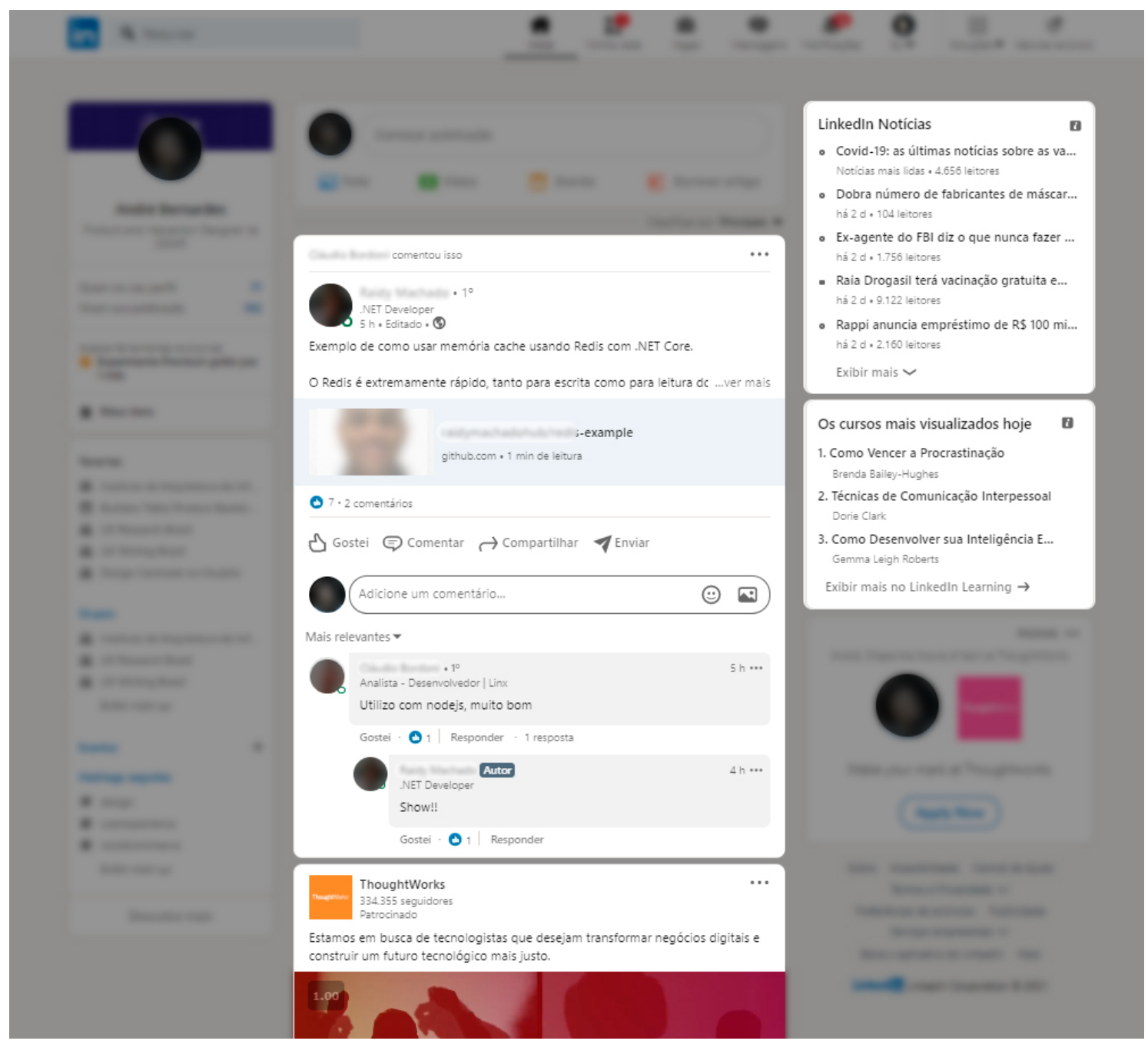

Na estrutura da página inicial do Linkedln, percebemos a categorização do menu superior em seis botões: a) início, que visa facilitar o retorno do usuário para a página inicial da rede social; b) minha rede, onde são visualizadas as solicitações de amizade e seguidores; c) vagas, na qual os usuários podem buscar por ofertas de trabalho em diversas categorias; d)

mensagens, que funciona semelhante ao chat padrão; e) em notificações é possível visualizar as atualizações das pessoas que você segue; e f) meu perfil, onde é possível configurar seus dados de usuário e informações de trabalho.

Na primeira coluna localizada na lateral esquerda, ficam visíveis as informações resumidas do usuário; abaixo, grupos e hashtags que ele segue. Na coluna central, estão todas as publicações em formato de feed com rolagem vertical infinita. Na terceira coluna, são listadas as últimas notícias do Linkedin. 


\section{Configuração}

Na configuração do Linkedln, podemos perceber a semelhança com outras redes sociais, como Facebook e Twitter. O menu superior e as três colunas demarcam a organização das informações mais acessadas na rede social (figura 6).

Podemos afirmar que este tipo de configuração é bem recebido pela maioria dos usuários de redes sociais, facilitando assim o reconhecimento e a navegação. Yablonski (2020) postula diversas "leis" oriundas da psicologia cognitiva para o design de experiências. A primeira é a Lei de Jakob, fazendo referência às heurísticas de Nielsen, e define seguinte premissa: "os usuários passam a maior parte do tempo em outros sites e preferem que seu site funcione da mesma maneira que todos os outros sites que já conhecem" (YABLONSKI, 2020, p. 1).

Figura 6: Análise da configuração do Linkedln.

Menu superior / Menu de navegação global
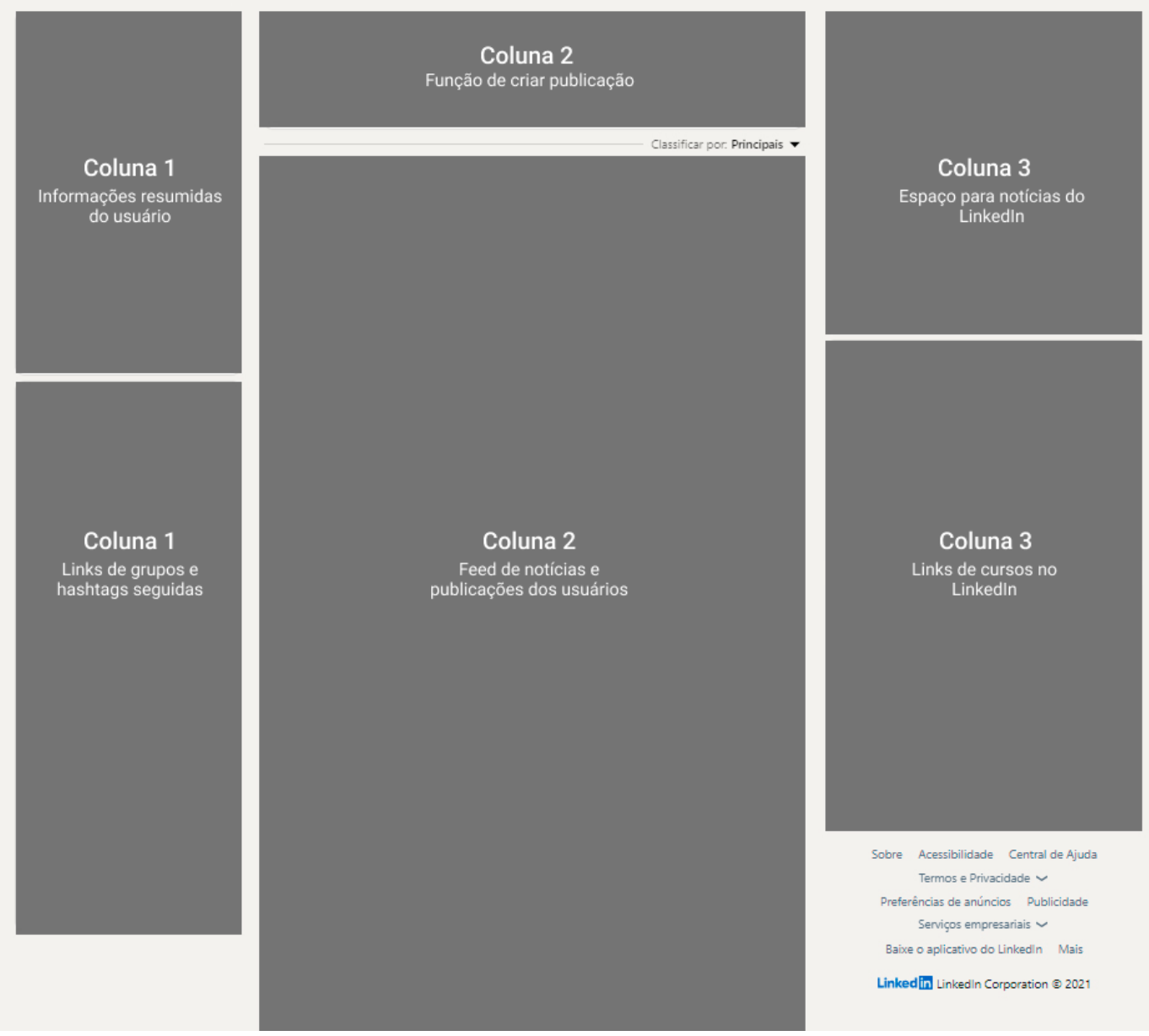

Sobre Acessibilidade Central de Ajuda Termos e Privacidade $\sim$ Preferências de anúncios Publicidade Senviços empresariais Baixe o aplicativo do Linkedin Mais Linked in Linkedin Corporation @ 2021 


\section{Modo}

A quarta variável definida por Twyman (1989) busca identificar o modo. Nesse contexto, tratase de apontar os tipos de linguagens utilizadas para a comunicação. No Linkedln, identificamos fortemente a utilização de linguagem verbal, pictórica e esquemática (Figura 7).

Figura 7: Análise do modo de comunicação verbal no Linkedln.

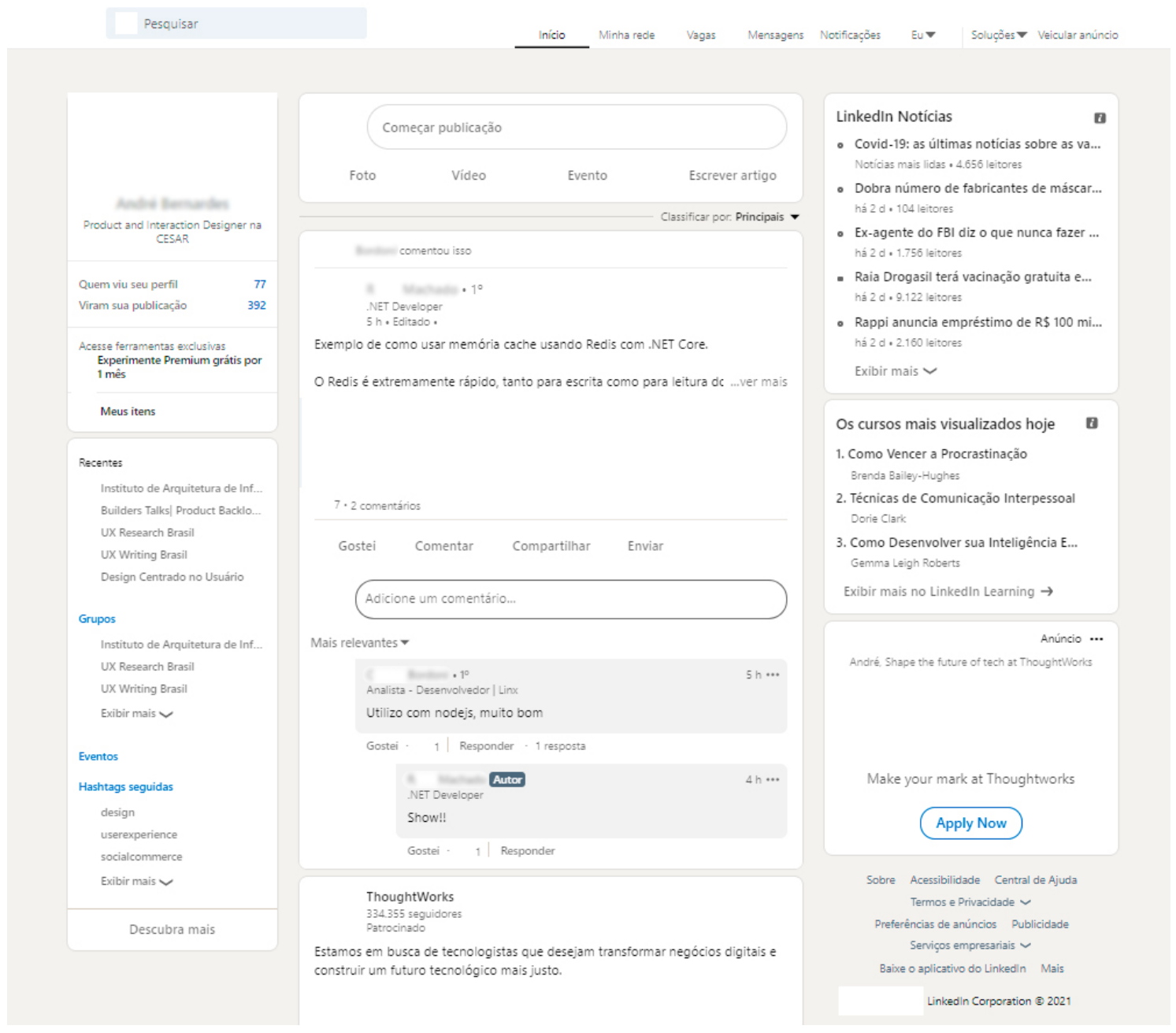


Figura 8: Análise do modo de comunicação pictórica no Linkedln.

Q

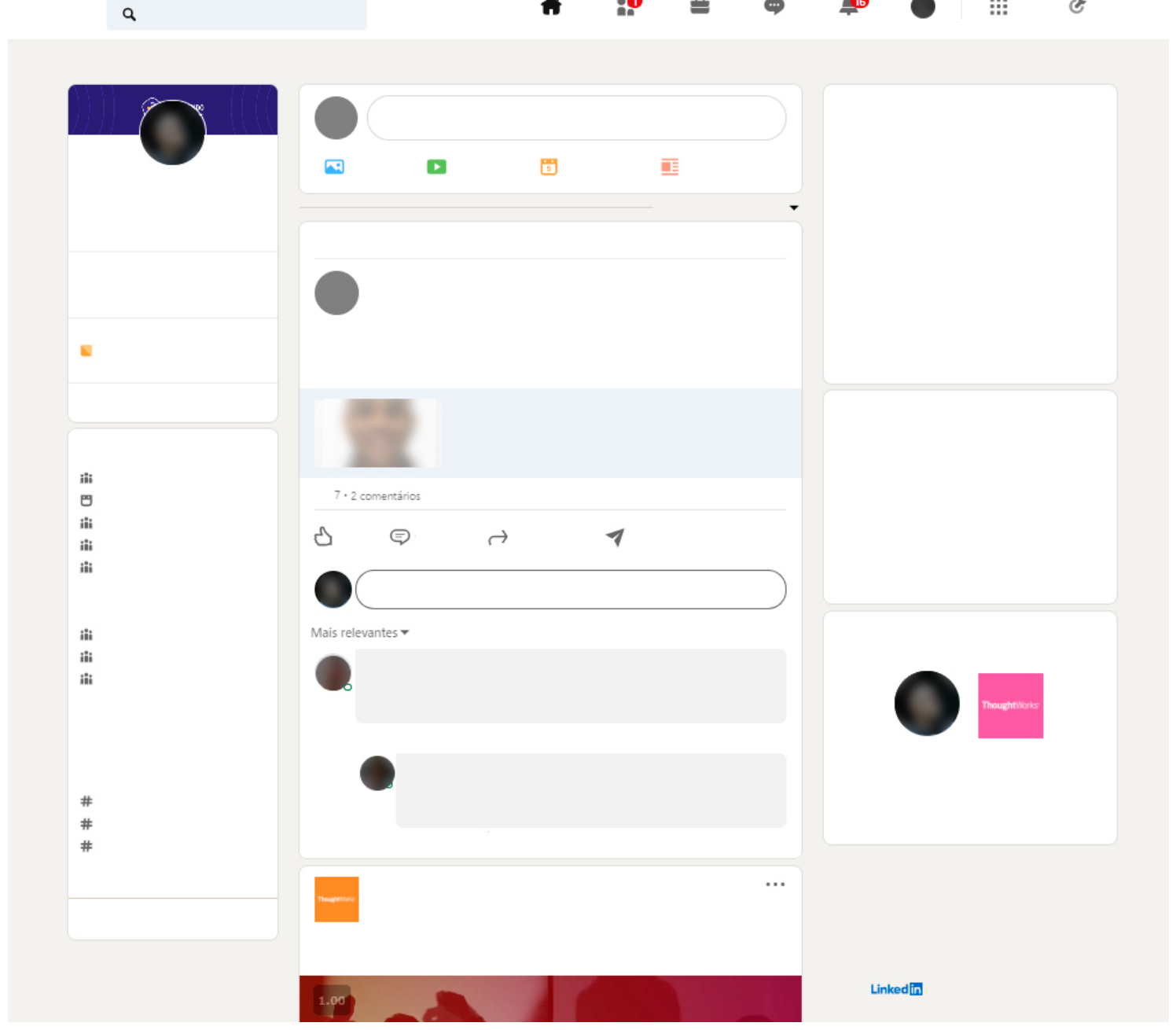

As áreas em branco presentes na Figura 8 em relação à Figura 7 mostram que a utilização da linguagem verbal ocupa grande parte da interface. A respeito da linguagem pictórica, identificamos a utilização de ícones que constituem um sistema baseado em metáforas visuais, visando facilitar a compreensão das categorias de informação. O uso de imagens preenche diferentes funções de comunicação no sistema, desde a imagem de identificação dos usuários, imagens de capa, variados tipos de publicação em imagem, slides, galeria e vídeos. O uso da linguagem esquemática segue a mesma lógica funcional, presente em ícones ou mesmo nas janelas de conteúdo. Portanto, observamos um predomínio da linguagem verbal estruturada pelo layout, de modo que as duas outras linguagens servem de apoio e diversificação; nesse sentido, imagens tendem a chamar mais atenção no feed.

\section{Meio de produção}

A quinta variável corresponde ao meio de produção. Podemos afirmar que a rede social utilizou recursos computacionais para sua produção assim como os usuários se utilizam de recursos digitais para inserir conteúdos na rede social. 


\section{Plataforma}

Na sexta variável, são avaliados recursos disponíveis na plataforma. Nesse aspecto, podemos afirmar que o Linkedln facilita a busca por vagas de trabalho e a conexão com outros profissionais do mercado de trabalho. Nesse sentido, a categoria de usuários compreende pessoas que estão inseridas ou pretendem se inserir no mercado de trabalho, que pode variar de 18 aos 60 anos de idade, com diferentes formações, experiências, habilidades e interesses.

\section{Circunstâncias de uso}

Por fim avaliamos a sétima variável, circunstâncias de uso. A interface da rede social apresenta grande robustez de componentes visuais, facilitando a interação e a compreensão dos recursos oferecidos. Não apresenta gatilhos que visam gerar estresse nos usuários, com ressalva dos conteúdos publicados pelos próprios usuários que podem gerar diferentes reações nos receptores.

\section{Considerações finais}

Utilizamos a semiótica para compreender a comunicação de maneira ampla, corroborando o uso proveitoso desse campo para o design de experiências. A análise inicial da interface da página home do Linkedln, onde foram aplicadas as variáveis da informação propostas por Twyman (1985), permitiu identificar o conteúdo informacional presente na rede social.

Buscamos um conhecimento mais aprofundado dos aspectos estruturais. Ao observar cada variável aplicada de forma prática e analítica, confirmou-se que o Linkedln possui forte ligação estrutural com as redes sociais Facebook e Twitter, confirmando a teoria compartilhada por Lorusso (2017) sobre a retórica da convivialidade (Davies, 2016) e a evidência do fato de que as pessoas têm preferência por um sistema que opere da mesma maneira que outros já conhecidos (Yablonski, 2020), o que facilita navegar pela interface (Krug, 2017).

A semelhança estrutural em relação aos concorrentes consiste de 1) um grid de três colunas como padrão bem aceito pela maioria dos usuários de redes sociais; 2) a localização centralizada do Feed de notícias com informações resumidas nas colunas laterais. Isso gera um reconhecimento com uma percepção de fácil uso, pois se repete em diversas interfaces do mesmo segmento. Assim, ele se apresenta e encoraja interações de maneira extremamente similar. Entretanto, o Linkedln declara um propósito diferente de outras redes sociais: conectar profissionais de diversas áreas de formação e níveis de experiência, permitindo assim o compartilhamento de vagas de trabalho em grandes, médias e pequenas empresas de forma fácil.

Portanto, a partir da discussão apresentada por Lorusso (2017), estudos futuros devem investigar em que medida ambientes tão semelhantes podem ter finalidades distintas. Além disso, é possível aprofundar o estudo sobre a percepção dos usuários em relação a utilização de linguagem não-verbal com a utilização de emojis e reactions dentro da interface do Linkedln. 


\section{Referências}

Davies, W. (2016). The Mismanaged Heart. Real Life Magazine. Recuperado em 01 maio, 2021, de https://reallifemag.com/the-mismanaged-heart

Dondis, D. (2015). Sintaxe da Linguagem Visual. São Paulo: Martins Fontes - selo Martins.

Hall, S. (2008). Isto significa isso. Isso significa aquilo: guia de semiótica para iniciantes (A. Mariz, trad.). São Paulo: Edições Rosari.

Krug. S. (2008). Não me faça pensar: uma abordagem de bom senso à usabilidade na web. Rio de Janeiro: Alta Books.

Lorusso, S. (2017). Linkedln Society. In F. Laranjo (Ed.), Design and democracy (pp. 65-75). Eindhoven: Onomatopee.

Niemeyer, L. (2013). Elementos de semiótica aplicados ao design. Rio de Janeiro: 2AB.

Rogers, Y. (2013). Design de interação: além da interação humano-computador (I. Gasparini, trad.). Porto Alegre: Bookman.

Santaella, L. (2005). O que é semiótica (Coleção primeiros passos, 103). São Paulo: Brasiliense.

Twyman, M. (1975). The significance of Isotype. In: Graphic communication through ISOTYPE, University of Reading, pp. 7-17.

Twyman, M. (1979). A Schema for the Study of Graphic Language. KOLERS, P.A. \& WROSTAD, M.E. \& BOUMA, H. (Eds.), In: The Processing of Visible Language (vol. 1, pp. 117- 150). Plenum.

Twyman, M. (1982). The graphic presentation of language. Information Design Journal, 3(1), pp. 2-22.

Twyman, M. (1985). Using pictorial language: a discussion of the dimensions of the problem. In T. M. Dufty and R. Waller (Eds.). Designing usable texts (pp. 245-312). Academic Press.

Unger, R., \& Chandler, C. (2008). O guia para projetar UX: A experiência do usuário (UX) para projetistas de conteúdo digital, aplicações e web sites (E. Oliveira, trad.). Rio de Janeiro: Alta Books.

Yablonski, J. (2020). Leis da psicologia aplicadas a UX. São Paulo: Novatec.

\section{Sobre os autores}

André D. B. Ferreira, Mestrando, CESAR School, Brasil <adbf@cesar.school>

Gabriela Araujo F. Oliveira, Doutoranda, UFPE/CESAR School, Brasil <gafo@cesar.school> 